Language and Language Teaching Journal http://e-journal.usd.ac.id/index.php/LLT Sanata Dharma University, Yogyakarta, Indonesia

\title{
READING HABITS IN DIGITAL ERA: A RESEARCH ON THE STUDENTS IN BORNEO UNIVERSITY
}

\author{
Firima Zona Tanjung, Ridwan, and Uli Agustina Gultom \\ Borneo University, Tarakan, Indonesia \\ english_zone@borneo.ac.id, ridwan.fkipubt@gmail.com, and \\ ulie_goeltoem@yahoo.com \\ DOI: doi.org/10.24071/11t.2017.200209
}

received 19 June 2017; revised 21 July 2017; accepted 24 September 2017

\begin{abstract}
This research aims to explore the current reading habits of university students. Moreover, it aims to determine the effects of widespread use of the internet and other digital resources in reading habits and to give some possible recommendation to improve students' reading habits in the digital era. The research design was descriptive survey research. The instrument of the research was questionnaire, which is based on Akarsu and Dariyemez (2014) and Chauhan and Lal (2012). The participants of the research were 320 students studying in six majors in Faculty of Teachers Training and Education at Borneo University. They were selected through the cluster random sampling. The questionnaire involved six categories, namely demographic information, frequency of items read, contents of online reading, online activities, content first clicked when online, and techniques to develop reading habits. All research data was analyzed using SPSS Statistics 22 program.
\end{abstract}

Keywords: reading habits, university students, digital era

\section{Introduction}

Nowadays, the easy access to digital media is a big challenge for reading habits. It gives an impact for everyone unexceptionally students. Certainly, students need technology in the form of internet to share, discuss, and process the information simultaneously. Their comfort of using technology e.g. smart phones or tab makes them prefer these devices than printed document. Additionally, it is a new kind of reading habits at which EFL students preferred internet-based reading than paper-based one (Shen, 2006). Further, internet enable people to learn something through rapid process and expect the contents in a concise and easy to digest format (Verma \& Malviya, 2014). Related to two previous statements, it can be considered that internet is popular among younger generation. Moreover, the numbers of these people are increasing significantly because they can gain information and entertainment easily through this media (Shahriza \& Hasan, 2007). Particularly, the shift of paper-based reading to internet-based reading is related to students' preference and motivation. They can have easy access to the source of information if they use digital resources. For example, as students, books are very important for them to have. However, today the way to get the information not only from printed version but "it can be through accessing 
electronic book at which they can save and then it can be taken anywhere with ease (Akarsu \& Dariyemez, 2014)". Thus, considering the explanation, this paper focused on answering following research questions: what are the major trends of reading interests and reading mediums of university students in Faculty of Teacher Training and Education at Borneo University Tarakan? how influential is the digital media on students' reading habits? and what are possible suggestions in order to improve students' reading habits in the digital era mainly at the university student level?

\section{Method}

Design of this research was descriptive survey research. This research aimed to make careful descriptions of educational phenomena so the researchers made use of both quantitative and qualitative approach. Related to the research objectives, the researchers used one-shot survey design at which the research instrument or tools given to the participants. The participants of this research were all university students from six majors in Faculty of Teacher Training and Education at Borneo University Tarakan. They were second year students. Most of them have studied English language around 8-10 years. The research procedure was displayed in figure 1 .

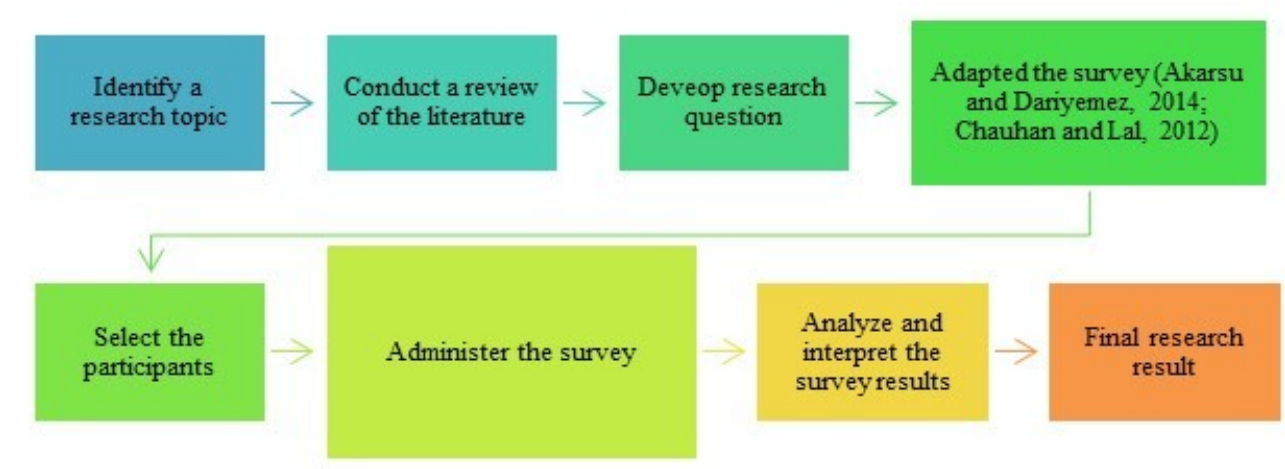

Figure 1. Steps in descriptive survey research (adapted from Lodico et al., 2010)

The researchers used a questionnaire to get the data of this research. The questionnaire was adapted from the work of Reading Habits Questionnaire (Akarsu \& Dariyemez, 2014), and the study result of Chauhan and Lal (2012) titled 'Impact of information technology on reading habits of college students'. The questionnaire was made online so that the students could respond it easily, anytime and anywhere. The questionnaire was launched in Bahasa and edited several times due to the suitable translation from the original version. It was part of considering the various background of departments from the participants involved in this research.

From 480 students who were expected to respond the questionnaire, there were 320 students who gave their response. The number of participants was reduced because of the multiple response given by the same participants and the 
number of students who were not active/taking leave of absence at the time the research being conducted.

\section{Findings and Discussion}

The major trends of students' reading interests and reading mediums in Faculty of Teacher Training and Education at Borneo University Tarakan.

Table 1. Demography of respondents

\begin{tabular}{lcc}
\hline \multicolumn{1}{c}{ Aspect of Demography } & Frequency & Percentage \\
\hline Gender & 74 & 23.13 \\
Male & 246 & 76.87 \\
Female & 320 & 100 \\
Total & & \\
Age & 306 & 95.63 \\
Under 20 years old & 13 & 4.06 \\
22-23 years old & 0 & 0 \\
24-25 years old & 1 & 0.31 \\
26-27 years old & 320 & 100 \\
Total & & \\
\hline
\end{tabular}

Due to the data collected, the gender who enrolled in Faculty of Teacher Training and Education were unbalanced at which the number of female students were greater than male ones. There were 246 females and 74 males. They were dominantly in the age of under 20 years old.

Table 2. Time spent on accessing internet daily

\begin{tabular}{lcc}
\hline Hours & Frequency & Percentage \\
\hline Less than 1 hour & 51 & 15.94 \\
$1-3$ hours & 105 & 32.81 \\
$3-6$ hours & 88 & 27.50 \\
More than 6 hours & 76 & 23.75 \\
Total & 320 & 100 \\
\hline
\end{tabular}

The above result showed that students mostly accessed internet every day because it enables them to gain information faster, cheaper, and more conveniently. It is supported with the result of finding stated by Shahriza \& Hasan (2007) that younger people are more familiar with the information and entertainment in a digital format. Certainly, they do not like to spend much time without getting what they want to know. Thus, using internet is considered as one of the ways to obtain information instantly without spending much time on topics they do not want to explore. It is easily done by inserting keywords and the information available all at once.

Table 3. Number of magazines the students read in a year 


\begin{tabular}{lcc}
\hline Number of Magazines & Frequency & Percentage \\
\hline None of Magazines & 70 & 21.88 \\
1 - 4 Magazines & 147 & 45.94 \\
5 - 9 Magazines & 66 & 20.63 \\
More than 9 Magazines & 37 & 11.56 \\
Total & 320 & 100 \\
\hline
\end{tabular}

As shown in Table 3, most of students (45.94\%) read 1-4 magazines, 20.63\% read 5-9 magazines, and $11.56 \%$ read more than 9 magazines. None of them $(21.88 \%)$ read any single magazine with a vary of reasons, e.g. they do not like reading magazines, there is no magazine, have no interest in reading magazines.

Table 4. Number of novels the students read in a year

\begin{tabular}{lcc}
\hline Number of Novels & Frequency & Percentage \\
\hline None of Novels & 44 & 13.75 \\
$1-4$ Novels & 142 & 44.38 \\
$5-9$ Novels & 78 & 24.38 \\
More than 9 Novels & 56 & 17.50 \\
Total & 320 & 100 \\
\hline
\end{tabular}

Considering the result in Table 4, most of students (44.38\%) read 1-4 novels, $24.38 \%$ read 5-9 novels, and $17.70 \%$ read more than 9 novels. None of them $(13.75 \%)$ like to read any novel with a vary of reasons, e.g. they do not know, they never read any novels, they do not like reading novels, there is no any new novel, etc.

Table 5. Frequency of items read

\begin{tabular}{ccccl}
\hline Reading & $\mathrm{N}$ & Mean & Std. Deviation & $\begin{array}{c}\text { Participation } \\
\text { Level }\end{array}$ \\
\hline Newspapers & 320 & 2.12 & 0.57 & Sometimes \\
Magazines & 320 & 1.88 & 0.53 & Sometimes \\
Text Books & 320 & 2.6 & 0.65 & Often \\
Novels & 320 & 2.36 & 0.76 & Sometimes \\
Emails & 320 & 2.08 & 0.68 & Sometimes \\
$\begin{array}{c}\text { Online } \\
\text { information }\end{array}$ & 320 & 3.03 & 0.79 & Often \\
\hline
\end{tabular}

Table 5 showed that the range of mean values were from 2.08 to 3.03 . Related to the available result, the least frequent number of the items was reading emails and the most frequent one was reading online information. The number of respondents who read newspapers, magazines, novels, and emails were included into the level of sometimes. Meanwhile, textbooks and online information were frequently read. Particularly, it indicated that they had a purpose in reading. Hence, indirectly there was a relationship between students' choice of reading materials and their reading purpose. As university students, they chose textbooks and online information as 
the materials they often read. In addition, respondent chose reading online information frequently because they liked to get fast and current information.

Table 6. Priority of reading materials the students read when online

\begin{tabular}{llc}
\hline Reading Material & Mean & Priority \\
\hline Online news & 2.82813 & 1 \\
Food/Nutrition & 2.7875 & 2 \\
Joke & 2.58438 & 3 \\
Health information & 2.54688 & 4 \\
Story and novel & 2.45625 & 5 \\
Sport & 2.45313 & 6 \\
Movie review & 2.44688 & 7 \\
Fashion & 2.40938 & 8 \\
Sale information & 2.25 & 9 \\
Journal articles & 2.24375 & 10 \\
Comic strips & 2.19688 & 11 \\
Job information & 2.1125 & 12 \\
E-books & 2.0375 & 13 \\
Emails & 1.98125 & 14 \\
Weather forecast & 1.9625 & 15 \\
Online magazine & 1.95 & 16 \\
\hline Horoscope & 1.6625 & 17 \\
\hline
\end{tabular}

The first priority of reading materials mostly chosen by the respondents was reading online information, followed by food/nutrition, then joke etc. This results pointed to the high rate of reading for general information (online news), in this sense, the students tend to read for pleasure/entertainment or for the purpose of grabbing rich of information for the sake of their own (top of five priorities related to their daily life matters) rather than reading for the academic purposes (reading journals or e-books). Surely, it is very contrast with the previous finding at which students chose textbook. However, getting back to the priority, they preferred choosing their daily needs fulfilment (both physically and mentally) to academics needs.

Table 7. Online activities

\begin{tabular}{lcc}
\hline \multicolumn{1}{c}{ Activities } & Yes (\%) & No (\%) \\
\hline I listen to music & 76.56 & 23.43 \\
I play games & 38.75 & 61.25 \\
I look at photos & 86.87 & 13.12 \\
I read all kinds of & 94.37 & 5.62 \\
information & & \\
I shop online & 40.62 & 59.37 \\
I use MSN & 42.18 & 57.81 \\
\hline
\end{tabular}




\begin{tabular}{|c|c|c|}
\hline \multicolumn{3}{|l|}{ messenger } \\
\hline I check my email & 51.25 & 48.75 \\
\hline I chat with friends & 96.87 & 3.12 \\
\hline $\begin{array}{l}\text { I downloaded } \\
\text { movies }\end{array}$ & 59.06 & 40.93 \\
\hline
\end{tabular}

The frequent activity done by the respondents was chatting with friends $(96.87 \%)$. It was followed by reading all kind of information (94.37\%) and looking at photos $(86.87 \%)$. Next, the respondents stated that that they listened to music $(76.56 \%)$ as their activities during online. From the number of activities done during online, students can be given some advices to do their activities in purpose of improving reading skills e.g. read all kinds of information and write the summary or key points of each, check and reply their emails, or facilitating their reading and writing skills simultaneously e.g. chatting with friends.

Table 8. Content first clicked when online

\begin{tabular}{lc}
\hline \multicolumn{1}{c}{ Category } & Percentage $\%$ \\
\hline Art and Humanities & 12.50 \\
Business and Economy & 9.06 \\
Computers and Internet & 21.56 \\
Education & 17.81 \\
Entertainment & 19.69 \\
Government & 0.31 \\
& 3.44 \\
Health & \\
News and Media & 5.94 \\
Recreation and Sports & 3.13 \\
Regional & 0.00 \\
Science & 0.31 \\
Social Science & 0.00 \\
Society and Culture & 0.94 \\
Facebook & 5.31 \\
\hline
\end{tabular}

The most frequent content first clicked when the respondents were online being about computer and internet $(21.56 \%)$. Then, it was followed by entertainment $(19.69 \%)$ and education (17.81\%). This result is interesting because majority of the respondents, as the university students, did not put education as the content first clicked when they were online. Instead, they chose about computer and internet then entertainment. Indeed, it strengthens the possible reason previously stated that they had a purpose of being entertained during surfing on internet.

To sum up, the respondents can be encouraged to access not only computer and internet or entertainment but they can be encouraged to access education as it is connected directly to their daily life as students. Though the number of respondents for accessing education content was still in the third place 
but it may become different if the lecturer makes use of some applications or make group on sites such as Edmodo as the media of learning and sharing so the students can develop their reading habits on education content too.

Table 9. Techniques to develop reading habits

\begin{tabular}{lccccc}
\hline \multicolumn{1}{c}{ Techniques } & $\mathrm{N}$ & Yes & Yes (\%) & No & No(\%) \\
\hline $\begin{array}{l}\text { Parental guidance \& } \\
\text { encouragement }\end{array}$ & 320 & 223 & 69.68 & 97 & 30.31 \\
$\begin{array}{l}\text { Motivation by teachers } \\
\begin{array}{l}\text { Reading materials } \\
\text { about hobbies and } \\
\text { interests }\end{array}\end{array}$ & 320 & 273 & 85.31 & 47 & 14.68 \\
$\begin{array}{l}\text { Consistent use of } \\
\text { dictionary }\end{array}$ & 320 & 192 & 60 & 128 & 40 \\
$\begin{array}{l}\text { Daily newspaper } \\
\text { reading }\end{array}$ & 320 & 99 & 30.93 & 221 & 69.06 \\
$\begin{array}{l}\text { Book reading } \\
\text { Visiting libraries }\end{array}$ & 320 & 287 & 89.68 & 33 & 10.31 \\
$\begin{array}{l}\text { Well-prepared reading } \\
\text { material }\end{array}$ & 320 & 217 & 67.81 & 103 & 32.18 \\
$\begin{array}{l}\text { Studying to improve } \\
\text { vocabulary knowledge }\end{array}$ & 320 & 304 & 95 & 16 & 5 \\
\hline
\end{tabular}

The most frequent technique to develop reading habits was reading materials about hobbies and interests $(96.25 \%)$. Hence, by providing many reading materials about hobbies and interests around the students' corner in the university, the respondents can be more motivated to develop their reading habits. Then, the technique in the second place was studying to improve vocabulary knowledge ( $95 \%$ ) followed by book reading $(89.68 \%)$. The respondents were still confident that these techniques could develop their reading habits. The more they read, the more vocabularies they master. The numbers of frequency became smaller for the options consistent use of dictionary (60\%) and daily newspaper reading (30.93\%). It was possibly connected to the speed and space needed to access by the respondents. As millennial generation, they preferred to use media that can access any information fast without time limit. That finding is supported by Shen' survey results (2006) at which EFL students' reading habits have shifted from paperbased to internet-based reading.

Related to the result of questionnaire, the respondents, studying in Faculty of Teacher Training and Education from a variety of departments, often enjoyed reading online information and textbooks. Particularly, it is closely related to the use of gadget among students such as smart phones or tabs which are simply exploited to access the current online news.

Next, besides they often read online news, they also frequently read textbooks. It indicated that students did their reading in purpose. As the university students, they preferred reading materials related to their needs in daily academic life. Further, related to the content first clicked when they were online, the 
respondents chose online news. The least popular items to choose was online magazine and horoscope. For the least popular item here, online magazine got more attention because in the previous questions, the respondents frequently chose reading 1-4 magazines. Hence, the use of internet for reading magazine was less popular than reading magazines in the printed version.

Considering all findings being displayed, the students of Faculty of Teacher Training and Education from various background of departments had particular level of reading habits. It is shown from the results at which they prefer reading online news and other types of reading materials. Yet, they also have had some preference on choosing media of reading items such as printed magazines rather than the online ones. Thus, it can be inferred that they have certain level of reading habits and also reading medium based on their preference simultaneously.

To answer the question about the widespread use of internet, the discussion is started from the duration of online surfing done by the students of Faculty of Teacher Training and Education. Related to the result, they spent their time between one up to three hours a day. Because these duration is average, the lecturers must consider it in order to make use of internet as the medium for developing students' reading habits. The ways can be done are through making group on sites, discussing more on the information, contents available online, maximizing the use of virtual class available in the university, and giving task sent via email. Hence, the use of internet will be fruitful as reading tool for students.

Additionally, during their online surfing, they did activities such as chatting with friends $(96.87 \%)$, reading all kind of information $(94.37 \%)$, looking at photos $(86.87 \%)$, and listening to music $(76.56 \%)$. Due to the activities done by the respondents, the lecturers can give recommended websites that enable students to improve their reading skills align with their reading habits. Later, related to the results of contents of reading materials being accessed, students had various texts to read. Therefore, they have used internet not only for obtaining information from the same sources every day. They like surfing different websites to get diverse materials.

Associated with the length of online time the students have every day, it can be a consideration for lecturers to stay connected and provide wide opportunity to students to use internet as the medium of learning through the task given or online discussion. Besides, all activities they always do can be directed to support students' reading habits. Thus, students should be given about what do's or dont's when online is needed in the purpose of increasing the effectiveness of using internet among students.

Reading skill has been challenged today by the existence and the popularity of internet. Nowadays, students feel more comfortable to read information instant through their smart phones or other digital sources. Shen (2006) stated that EFL students' reading habits have shifted from paper-based to internet-based reading. Considering the popularity of internet among youngsters as the highest numbers of internet users, several possible recommendations can be done in order to improve students' reading habits in the digital era.

First, their reading habits should be developed by integrating the use of communication or digital devices in classroom activities. Here, the responsibility 
of lecturers is very important because they can give motivation to the students as it was represented in the questionnaire result $(85.31 \%)$. Lecturers play a significant role to direct and supervise students in accessing the online sources of reading appropriate with their needs as youngsters and scholars.

Second, as reading connected to other skills in language such as listening, writing, and speaking, it is meaningful to inform students that they may have various ways of interacting with their classmates. One of them is through chatting live on some sites such as Facebook or other sites that enable them to do so. The topics they have to discuss with their friends may vary appropriate with their interest. Certainly, the topics of discussion can be taken from any sources. This activity, precisely, combines multiple skills to practice such as listening and speaking. The other thing is lecturers may give students task of taking different reading online texts aligned with the learning materials and ask them to write their understandings in the form of argumentative essays or any other types of writing. Thus, they can have benefit from their reading activities in order to improve writing skill.

Third, the possible recommendation to improve students' reading habit is organizing events related to reading especially done by academic institutions. The events may be in the form of "study circle, debate clubs, seminars, essay competitions, quiz competitions (Akanda, Hoq, \& Hasan, 2013)". For example, if language department organizes poem reading competition, the committee can open the opportunity for the youngsters to compete and read poems aloud in front of public. Certainly, it is to develop the youngsters' self-confidence. Besides, it can also develop their reading habits. The more contests being organized; the more participants especially young generation get involved in the effort of making reading as part of their culture. Moreover, the habits of youngsters can be more developed through games. It will be fun and meaningful for them to participate and try their best. In short, the participants will read a lot and use all information they have to compete in the reading competition. Hence, unconsciously, it is one of the alternative things can be done to develop their reading habits.

As well as organizing reading contests, the fourth recommended thing is providing more books available to students around their environment so that their interest in reading can be increased (Akanda, Hoq, \& Hasan, 2013). Not only books, the students are also provided with the interesting and various content of the reading materials. Hence, lecturers should make use of texts, pictures, and any other texts to be discussed inside or outside class. It is also to minimize students' boredom on same materials being used along the class session in one semester.

Fifth, students will pay their attention on reading materials which are accessible in anytime and anywhere. Thus, the easy access to websites and other online sites enable them to keep their interest in reading. It is as recommendation for the policy makers in university to provide more online access and books for students. Moreover, all educators at the faculties in the university can hold reading campaigns by inviting more influential or inspiring figures so the students will be more attracted to participate in the reading events. The campaigns can be in the form of reading week, reading hour (Akarsu \& Dariyemez, 2014). These activities are recommended to be held in and out of the classroom. Therefore, the students 
will not consider reading as the only thing they have to do in the classroom during teaching learning process but it is the activity that they need to do as part of their daily lives.

As the final recommendation, it is very needed to attract youngsters or $\mathrm{Y}$ generation in the effort of maintaining balance in the use of gadgets and traditional reading. Together, librarians and educators warn about the effect of "time eating machines" that can influence the youngsters themselves (Loan, 2009). If they pay more attention on those machines, it will influence the education systems reorganization (Akarsu \& Dariyemez, 2014). Thus, the optimal use of technology and traditional reading should be kept balance so students are not addicted to the devices at all. Yet, they can determine when, where, how, and what they read appropriate with their reading purposes and the availability of the medium.

Overall, all aspects should participate actively in the effort of developing reading habits starting from the students themselves, educators, librarians, figures, and society. The support they bring, particularly, will give an impact on creating Indonesian future generation having strong literary power.

\section{Conclusion}

As this article has outlined, the advances in technology alter people interest on reading from printed version to digitalized one. They prefer using gadgets to read information every day. It is supported by the length of their time accessing internet which is approximately one up to three hours a day. Nevertheless, they also have had some preference on choosing reading medium such as printed magazines rather than the online ones. Thus, it can be said they have particular level of reading habits and reading medium based on their preference simultaneously.

The use of technology in the classroom can be a consideration for lecturers to stay connected with their students. But realizing the widespread use of internet as part of technology advancement, lecturers should explain what do's or dont's when students search for information. It has to be done in the purpose of increasing the effectiveness of using internet as reading medium among students.

Active participation in the effort of developing reading habits should be done by all elements starting from the students themselves, educators, librarians, figures, and society. Without the cooperation among those elements, reading is never part of the culture. Yet, if it is considered seriously and supported wholly can bring a good impact for bringing reading not only as habits but also culture mainly in Faculty of Teacher Training and Education at Borneo University and broadly in Indonesia.

\section{References}

Akanda, A.K.M., Ali, E., Hoq, K.M.G., \& Hasan, N. (2013). Reading habit of students in social sciences and arts: A case study of Rajashahi University. Chinese Librarianship: An International Electronic Journal, 35. Retrieved on August 20, 2017 from http://www.iclc.us/cliej/c135AHH.pdf 
Akarsu, O. \& Dariyemez, T. (2014). The reading habits of university students studying English language and literature in the digital age. Journal of Language and Linguistic Studies, 10(2), 85-99. Retrieved on May 20, 2016 from: dergipark.ulakbim.gov.tr/jlls/article/download/.../5000078393

Chauhan, P., \& Lal, P. (2012). Impact of information technology on reading habits of college students. International Journal of Research Review in Engineering Science and Technology, 1(1), 101-106. Retrieved on May 15, 2016 from: http://citeseerx.ist.psu.edu/viewdoc/download?doi=10.1.1.300.7473\&rep=re p1\&type $=$ pdf

Loan, F. A. (2009). Impact of new technology on reading habits: A glimpse on the world literature. Unpublished manuscript. Retrieved on May 21, 2016 from: http://eprints.rclis.org/20084/1/NCERT.pdf

Lodico, M., Spaulding, D., \& Voegtle, K. (2010). Methods in educational research: From theory to practice. San Francisco, CA: John Wiley \& Sons, Inc.

Shahriza A.K.N., \& Hasan, A. (2007). Reading habits and attitude in the digital age: Analysis of gender and academic program differences in Malaysia. The Electronic Library, 25(3), 285-298. Retrieved on May 20, 2016 from:https://www.researchgate.net/profile/Nor_Abdul_Karim/publication/2 20677317_Reading_habits_and_attitude_in_the_digital_age_Analysis_of_ gender_and_academic_program_differences_in_Malaysia/links $/ 55 \mathrm{e} 6 \mathrm{aefd} 0 \overline{8}$

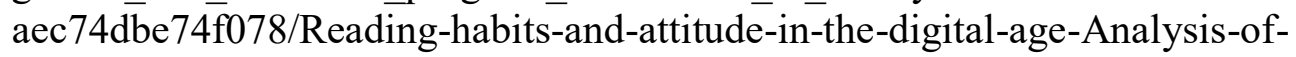
gender-and-academic-program-differences-in-Malaysia.pdf

Shen, L. (2006). Computer technology and college students' reading habits. Chia-nan Annual Bulletin, 32, 559-572. Retrieved on May 20, 2016 from: http://citeseerx.ist.psu.edu/viewdoc/download?doi=10.1.1.526.1818\&rep=re $\mathrm{p} 1 \&$ type $=\mathrm{pdf}$

Verma, Jyoti, \& Malviya, V. (2014). The impact of internet and digital media on reading habit. XXIV National Seminar of the IASLIC, 50. Retrieved on May 20 , 2016 from: https://www.researchgate.net/publication/234264060_The_Impact_of_Inter net_and_Digital_Media_on_Reading_Habit 